\title{
Altered blood glucose dynamics during and after anhepatic phase of liver transplantation: a model-based approach
}

\author{
József Homlok*, J . Geoffrey Chase**, Balázs Benyó*, Katalin Kovács*** \\ *Budapest University of Technology and Economics/Dept. of Control Engineering and Information Technology, \\ Budapest, Hungary \\ **University of Canterbury/Dept. of Mechanical Engineering \\ Christchurch, New Zealand \\ ***Széchenyi István University/Dept. of Information Technology \\ Győr, Hungary \\ e-mail: homlokj@iit.bme.hu, geoff.chase@canterbury.ac.nz, bbenyo@iit.bme.hu, kovacsk@sze.hu
}

\begin{abstract}
During liver transplantation (LT) the glucose metabolism is effected by a crucial disturbance. The blood glucose level is extremely hard to control by conventional clinical protocols during this phase. Model based approach can enhance the blood glucose control during the anhepatic phase and postanhepatic phase. The physiological constants of validated clinical metabolic model were slightly modified based on previous studies. The model fitting errors and the sufficient capture of the blood glucose (BG) dynamic evincived the applicability of the model. However the particular/sufficient per-patient estimation of endogenous production could more enhance the performance of the model based BG prediction.
\end{abstract}

\section{INTRODUCTION}

The Liver plays an important role maintaining the glucose metabolic balance in the organism. Nutrient rich blood, coming from the intestines reaches first the liver through the portal vein. Based on it's anatomical position, besides it's filtering function, the liver developed to maintain the homeostasis, ensuring a constant blood glucose metabolism in the peripheral organs and tissues [1]. On the strength of the blood-level, the liver can uptake glucose from the blood for short, medium and long term storage in several form. In post-absorptive condition, it can be considered as the main source of the endogenous glucose production EGP.

The process of the liver transplantation can be divided into three main phases. The first steps is the so called pre-anhepatic phase (pre-AH), the second is the anhepatic phase $(\mathrm{AH})$ and the third is the post-anhepatic phase (post-AH) or reperfusion step. The anhepatic phase refers to the absence of the liver.

During liver transplantation (LT), the absence of liver, causes enormously disturbance in the maintaining function. As a consequence the variability of the blood glucose (BG) concentration increases during the surgery, particularly after reperfusion phase [2] [3], it can be seen also on Fig. 2. The appropriate management of the metabolism in these phases towards reduction of the $\mathrm{BG}$, would promote the recovery of the liver-transplanted patients [4].
There's a metabolic model (ICING2), which can tolerate despite the high level inter- and intra patient variability at intensive care unit (ICU), modeling the human metabolic system. On the strength of previous studies [3] the ICING2 model in certain phase of the surgery (anhepatic phase and post-anhepatic phase after reperfusion) is only able to reproduce the clinical measured values with particular error. In the course of the recent study the possible necessary modifications were analyzed in the interest of the accurate modeling of the metabolic system during liver-transplantation.

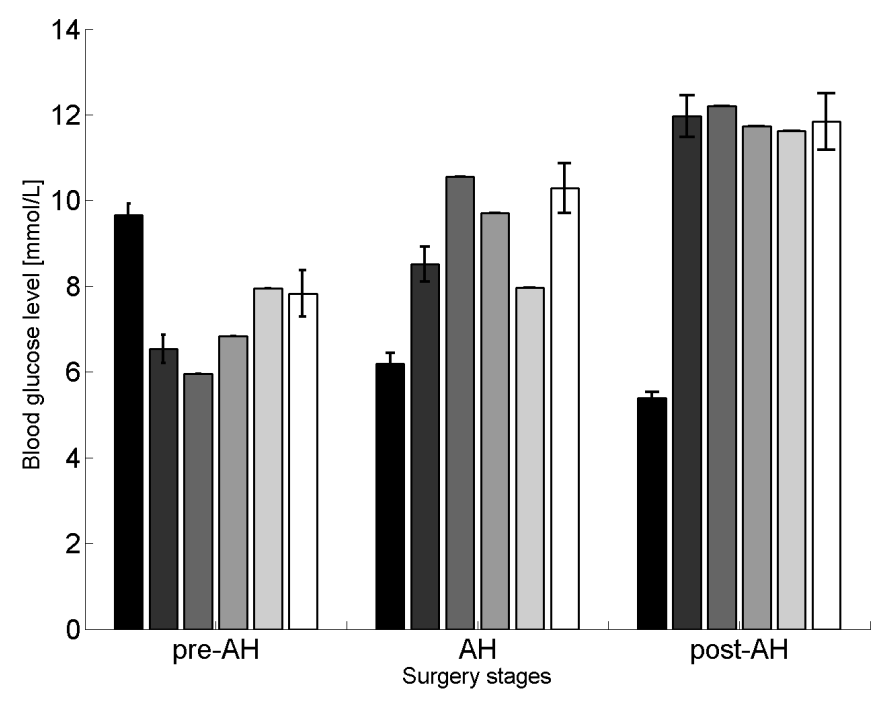

Fig. 1. Blood glucose $(B G)$ trends (Mean \pm SE) during the surgery phases; pre-AH (pre-anhepatic), AH (anhepatic), post-AH (post-anhepatic). The data were obtained from several studies [5], [6], [7] (in accordance with the barorder, the last three without SE were obtained from the same paper), the white face color bar represent the recent measurements. The measurements except the first bar show a high rate of correlation. 


\section{Methods}

The aim of this study was to prove the applicability of a clinical valid ICU metabolic model for liver-transplantation (LT) settings. This section concentrates on the recently measured clinical data, the metabolic model, the researches on the variation of physiological factors during liver transplantation and the synthesis of the results of the methods, listed above.

\section{A. Data}

The data of 13 orthotopic liver transplanted (OLT) patients were sampled at the Transplantation and Surgery Clinic in Budapest. The blood glucose levels were measured by Astrup blood gas analysis apparatus. Additionally all insulin, glucose infusion data were recorded, just as the times for each major surgical steps; 1) liver hepatectomy, 2) reperfusion through the portal vein, 3) reperfusion through the hepatic aorta. The average length of the anhepatic status was $80.4 \pm 27$ minutes. During the surgery a significant increase can be discovered, which proved to be independent of the administration of exogenous glucose or insulin [2] [3] (Fig. 2).

\section{B. Metabolic model}

The ICING2 (Intensive Control Insulin-Nutrition-Glucose) is a clinically validated metabolic model [8]. The model describes the function of the metabolic system, the uptake and the release of glucose in the body. It also includes the aspiration function of the liver to maintain the homeostasis. The model describes the glucose release of the liver by the endogenous glucose production $E G P$, and the endogenous glucose clearance $p_{G}$. The factors are listed in the Table I. The $G$ refers to the plasma glucose concentration, the $Q$ to the interstitial insulin concentration, $I$ to the plasma insulin concentration. The evolution of the variables are described by the Equations (1-7).

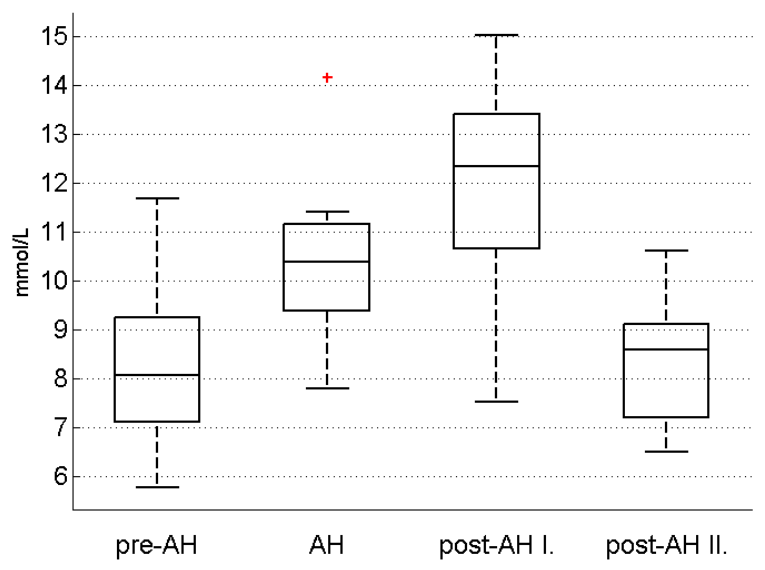

Fig. 2. Blood Glucose level trends with IQR during LT surgery of 12 patients; pre-AH (pre-anhepatic), AH (anhepatic), post-AH (post-anhepatic). According to the blood glucose (BG) variability the post-anhepatic phase can be divided in two sub-phases.
TABLE I

PHYSIOLOGICAL CONSTANTS USED IN ICING2 FOR ICU TREATMENT [8] [9]

\begin{tabular}{|c|c|c|}
\hline $\begin{array}{l}\text { Model } \\
\text { var. }\end{array}$ & Description & $\begin{array}{l}\text { Numerical } \\
\text { value } \\
\text { [typical } \\
\text { range] }\end{array}$ \\
\hline$p_{G}$ & Endogenous glucose clearance & $0.006 \mathrm{~min}^{-1}$ \\
\hline$S_{I}$ & Insulin sensitivity & \\
\hline$\alpha_{G}$ & $\begin{array}{l}\text { Saturation of insulin- } \\
\text { dependent glucose clearance } \\
\text { and receptor-bound insulin } \\
\text { clearance from interstitium }\end{array}$ & $165 \mathrm{LmU}$ \\
\hline$d_{1}$ & $\begin{array}{l}\text { Rate of glucose transfer be- } \\
\text { tween the stomach and gut }\end{array}$ & $\frac{-\ln (0.5)}{20} \min ^{-1}$ \\
\hline$d_{2}$ & $\begin{array}{l}\text { Rate of glucose transfer from } \\
\text { the gut to the bloodstream }\end{array}$ & $\frac{-\ln (0.5)}{100} \min ^{-1}$ \\
\hline$P_{\max }$ & $\begin{array}{l}\text { Maximal disposal rate from } \\
\text { the gut }\end{array}$ & $6.11 \mathrm{mmol} / \mathrm{min}$ \\
\hline$E G P_{b}$ & $\begin{array}{l}\text { Basal endogenous glucose pro- } \\
\text { duction (unsuppressed by glu- } \\
\text { cose and insulin concentration) }\end{array}$ & $1.16 \mathrm{mmol} / \mathrm{min}$ \\
\hline$C N S$ & $\begin{array}{l}\text { Non-insulin mediated glucose } \\
\text { uptake by the central nervous } \\
\text { system }\end{array}$ & $0.3 \mathrm{mmol} / \mathrm{L}$ \\
\hline$V_{G}$ & Glucose distribution volume & $13.3 L$ \\
\hline$n_{I}, n_{C}$ & $\begin{array}{l}\text { Rate of transport between } \\
\text { plasma and interstitial insulin } \\
\text { compartments }\end{array}$ & $0.0061 / \mathrm{min}$ \\
\hline$\alpha_{I}$ & $\begin{array}{l}\text { Saturation of plasma insulin } \\
\text { clearance by the liver }\end{array}$ & $1.7 e-3 L / m U$ \\
\hline$V_{I}$ & Insulin distribution volume & $4 L$ \\
\hline$x_{L}$ & $\begin{array}{l}\text { First-pass hepatic insulin clear- } \\
\text { ance }\end{array}$ & $0.67-$ \\
\hline$n_{K}$ & $\begin{array}{l}\text { Clearance of insulin from } \\
\text { plasma via the renal route }\end{array}$ & $0.05421 / \min$ \\
\hline$n_{L}$ & $\begin{array}{l}\text { Clearance of insulin from } \\
\text { plasma via the hepatic route }\end{array}$ & $0.15781 / \min$ \\
\hline
\end{tabular}

$$
\begin{aligned}
\dot{G}=- & p_{G} \cdot G(t)-S_{I} G(t) \frac{Q(t)}{1+\alpha_{G} Q(t)} \\
& +\frac{P(t)+E G P_{b}-C N S+P N(t)}{V_{G}} \\
\dot{I}=- & \frac{n_{L} I(t)}{1+\alpha_{I} I(t)}-n_{K} I(t)-(I(t)-Q(t)) n_{I} \\
& \quad+\frac{u_{e} x(t)}{V_{I}}+\left(1-x_{L}\right) \frac{u_{e n}}{V_{I}} \\
\dot{Q}= & (I(t)-Q(t)) n_{I}-n_{C} \frac{Q(t)}{1+\alpha_{G} Q(t)} \\
\dot{P}_{1}=- & d_{1} P_{1}+P(t) \\
\dot{P}_{2}= & -\min \left(d_{2} P_{2}, P_{\max }\right)+d_{1} P_{1} \\
u_{e n}= & k_{1} e^{-I(t)^{k_{2} / k_{3}}} \\
P(t)= & \min \left(d_{2} P_{2}, P_{\max }\right)+P N(t)
\end{aligned}
$$




\section{Previous studies on liver transplantation caused metabolism variation}

A number of studies have been carried out on analyzing the variation of glucose metabolism during liver transplantation . The glucose levels were measured frequently, furthermore they focused on the changes in endogenous glucose production (using dilution methods with several tracers, or analytical methods, derivation of other quantities) and the glucose clearance. In addition the rate of the changes in circulation, like the glucose distribution volume (glucose space) or the femoral blood pressure [5]. Also the concentration change of substance-levels was recorded (sodium, potassium) [10] as well as the hormone-levels like c-peptide, alanine, glutamine; these concentrations also refer to the extrahepatic functions of glucose release and uptake [5] [11] [12] [13].

In the terms of the recent study one relevant factor is the development of blood glucose concentratio. Atchison et al.[2] reported an intensive increase of $\mathrm{BG}$ level during $\mathrm{AH}-$ phase and even more intensive increase after the reperfusion rate. They proved also it's independence of any exogenous glucose and insulin administration. These data seem to be consistent with the recent clinical measurements Fig. 2 and the experiences of Tsinary et al. [6] and Kim et al. [7], only Battezzati et al. [5] reported difference BG evolution tendency in $\mathrm{AH}$ and post-AG sections.

The determination of extra-hepatic endogenous glucose production (EGP) was followed by elevated focus of interest in the recent time. The researches could be divided into several subgroups; one part of the studies measured or estimated analytical way the EGP during LT [15], the other one was to measure the EGP by dilution method in post-absorptive state [5] [13] [12], another group stimulated the metabolic system by glucose and insulin clamps [11]. All of the studies were to identify the renal contribution (Kidney) to the EGP. The contribution of the kidney to the EGP is estimated about $25-35 \%$ in post-absorptive state [12] [13], the contibution in anhepatic phase according to the studies counts for $50-60 \%$ [5] [15] of the baseline (average healthy state). The present study uses the results, listed on the Table II and Table III.

\section{Model parameter settings \& Model fitting design}

In the phases of the surgery, the constants describing the metabolic function, change as described in the previous section (Table III, EGP Glucose Space, Glucose Clearance). The recent clinical measurements' and other studies measurements show a high correlation in statistical data in each surgical phases (Fig. 1). Considering this fact, the results of the previous researches on the topic, can be inserted in the ICING2 model. In addition the model contains such metabolic functions describing factors, which highly effected by the liver function. In absence of the liver based on that fundamental physiological considerations they can be set to zero (clearance of insulin form plasma via the hepatic route the first pass hepatic insulin clearance). The time-function of the data should be also analyzed; the hepatic function, and also the metabolic function was considered to be normal in pre-anhepatic phase
TABLE II

BLOOD GLUCOSE EVOLUTION UNDER LIVER TRANSPLANTATION, RESULTS [MEAN+ SE] OF PREVIOUS RESEARCHES. Tsinari et al. [6] CLASSIFIED THE PATIENTS BY THE PHYSICAL STATUS ON THE STRENGTH OF THE RECOMMENDATION OF AMERICAN SOCIETY OF ANESTHESIOLOGISTS (ASA)

\begin{tabular}{lllll}
\hline Ref. & Unit & pre-AH & AH & post-AH \\
\hline [5] & $m g / d l$ & $174 \pm 11$ & $111.24 \pm 0.26$ & $97 \pm 10$ \\
[7] & $m g / d l$ & $117.6 \pm 32.9$ & $153.2 \pm 39.8$ & NaN \\
ASA III [6] & $m g / d l$ & 107.3 & 190 & 219.77 \\
ASA IV [6] & $m g / d l$ & 123.13 & 174.7 & 211.04 \\
ASA V [6] & $m g / d l$ & 143 & 143.33 & 209.33 \\
\hline
\end{tabular}

TABLE III

EXTRACTED PHYSIOLOGICAL PARAMETERS, REFERRING TO THE CHANGES DURING ANHEPATIC PHASE

\begin{tabular}{lcclll}
\hline Parameters & Ref. & unit & pre-AH & AH & post-AH \\
\hline \multirow{2}{*}{ EGP } & {$[15]$} & $\frac{m g}{k g m i n}$ & 2.6 & 1.38 & NaN \\
& {$[5]$} & $\frac{\mu m o l}{k g m i n}$ & NaN & 9.5 & NaN \\
& {$[5]$} & $\%$ & NaN & 65 & NaN \\
$\begin{array}{l}\text { Glucose } \\
\text { space }\end{array}$ & {$[5]$} & $\%$ & baseline & 75 & baseline \\
$\begin{array}{l}\text { Glucose } \\
\text { clearance }\end{array}$ & {$[5]$} & $\%$ & baseline & 75 & NaN \\
\hline
\end{tabular}

(assumption for the renal contribution of the EGP), and already one hour after the reperfusion, as a result, the variation of the parameters was carried out for the anhepatic phase.

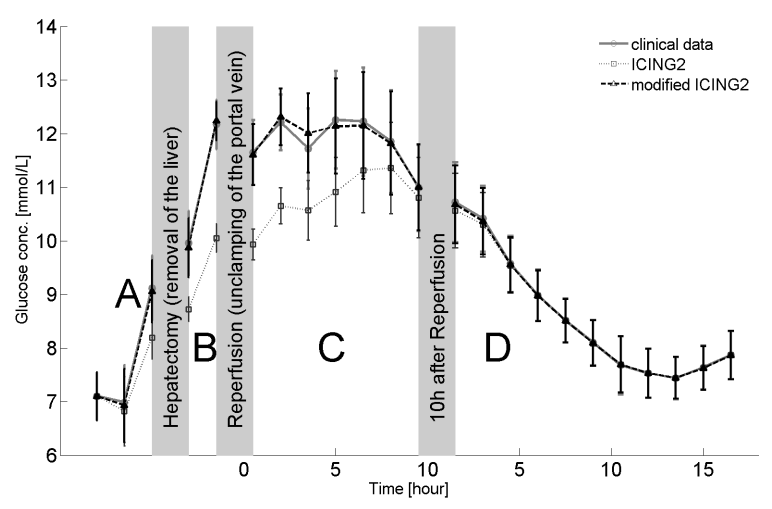

Fig. 3. The Comparison of Blood Glucose evolution of the statistical data of the clinical measurements, ICING2 model, and the modified ICING2 model. The figure represents the important steps of the surgery; A the pre-anhepatic phase, $\mathrm{B}$ is the anhepatic phase, $\mathrm{C}$ regards to the post-anhepatic phase after the reperfusion

\section{RESULTS}

After the modification of the original model parameters during the anhepatic phase, the clinical measurements and the results of the model fitting are shown on the Fig. 3.

On the basis of the main steps of the surgery, the time of the study were divided into the following phases; A (preanhepatic), B (anhepatic), C (post-anhepatic I) and D (post- 
TABLE IV

MAPE (MEAN ABSOLUTE PERCENTAGE ERROR) [\%] ERROR OF THE WHOLE COHORT FOR THE CERTAIN PHASES

\begin{tabular}{lcc}
\hline Phase & ICING2 orig. & ICING2 mod. \\
\hline pre-anhepatic & 5.056 & 0.892 \\
anhepatic & 11.901 & 2.939 \\
post-anhepatic I. & 7.842 & 1.567 \\
post-anhepatic II. & 0.541 & 0.553 \\
\hline
\end{tabular}

anhepatic II). Between the phases the surgery steps were indicated (removal of the liver, unclamping of the portal vein). The Figure 3 represents the statistical data of clinical measurements, as well as the simulations of whole patient cohort. The lengths of the phases A and B at each patients are different thus the time was normalized in these cases. During the $\mathrm{C}$ and $\mathrm{D}$ phases the horizontal axis represents the elapsed time in hours.

The fitting of the original ICING 2 model differs from the clinical measurements during the anhepatic time, and thus during the approximately 10 hours after reperfusion high variable interval until the normalization of the glucose metabolism (post-anhepatic II).

As a results of the modified parameters during the $\mathrm{B}$ phase, the ICING2 is able to follow the increase and the variability of the blood glucose level dynamic (Table IV).

\section{Discussion \& CONCLUSION}

The fitting results (Fig. 3, Table. 4.) of the modified ICING2 model denotes it's applicability for the assistance of glucose management during liver transplantation (LT). As the results of the change of the physiological constants $(E G P, V g)$ according to the previous studies and the varying of the factors describing the glucose metabolism $\left(P g, n_{L}, u_{e n}\right)$, the fitting of the model was able to capture the highly variable dynamic of the blood glucose (BG) concentration also in the anhepatic phase and the post- anhepatic phase after the reperfusion properly.

The results of previous researches, which discovered the changes of glucose metabolism during LT, inserted into the ICING2 model, it is appropriate for the prediction 1 and thus for the control of blood glucose (BG) level during LT, enhancing the recruitment of the patients. The recent model fitting proves the assumption about the existence of non-hepatic EGP (endogenous glucose production). However for the shake of the accurate knowing of the whole glucose metabolism during liver transplantation makes the identification of the proper function of EGP and insulin sensitivity necessary.

\section{ACKNOWLEDGMENT}

This work was supported by the Hungarian National Scientific Research Foundation, Grants No. T80316 and T82066 and the EU FP7 IRSES eTime Grant No. 318943. The research work of József Homlok is supported by the Richter Scholarship.
The authors thank for Csaba Turi, for his work in collecting and systematizing the measurements data and the times of substantial stages during the surgery.

\section{REFERENCES}

[1] Gertrud Rehner and Hannerlore Daniel, "Die Leber als multifunktionelles Organ," in Biochemie der Ernährung, H. D. Gertrud Rehner, Ed. Spektrum Akademischer Verlag Heidelberg, 2010, ch. 9, pp. 409487.

[2] S. R. Atchison, S. R. Prettke, G. A. Fromme, T. A. Janossy, and S. E. Kunkel, "Plasma glucose concentration during liver transplantation," Mayo Clinic Proceedings, vol. 64, pp. 241-245, 1989.

[3] J. Homlok, J. G. Chase, C. Turi, and B. Benyó, "Comparison of model based and clinical blood glucose evolution during and after anhepatic status," 2013.

[4] J. B. Ammori, M. Sigakis, M. J. Englesbe, M. O’Reilly, and S. J. Pelletier, "Effect of intraoperative hyperglycemia during liver transplantation," Journal of Surgical Research, vol. 140, pp. 227-233, 2007.

[5] A. Battezzati, A. Caumo, F. Martino, L. P. Sereni, J. Coppa, R. Romito, M. Ammatuna, E. Regalia, D. Matthews, V. Mazzaferro, and L. Luzi, "Nonhepatic glucose production in humans," American journal of physiology. Endocrinology and metabolism, vol. 286, no. 1, pp. E129-E135, 2004.

[6] K. K. Tsinari, E. P. Misiakos, C. T. Lawand, M. A. Chatzipetrou, K. V. Lampadariou, A. Bakonyi Neto, J. C. Llanos, S. Tamura, A. R. Gyamfi, and A. G. Tzakis, "Factors affecting metabolic and electrolyte changes after reperfusion in liver transplantation." Transplant Proc, vol. 36, no. 10, pp. 3051-6, 2004. [Online]. Available: http://www.biomedsearch.com/nih/Factorsaffecting-metabolic-electrolyte-changes/15686692.html

[7] D.-Y. Kim, I. Y. Huh, Y. Woo Cho, E. Sun Park, S. Eun Park, Y. Won Nah, and C. Ryul Park, "Experience without using venoveno bypass in adult orthotopic liver transplantation," Korean J Anesthesiol, vol. 60, pp. 19-24, 2011.

[8] J. Lin, N. N. Razak, C. G. Pretty, A. J. Le Compte, P. Docherty, J. D. Parente, G. M. Shaw, C. E. Hann, and J. G. Chase, "A physiological intensive control insulin-nutrition-glucose (icing) model validated in critically ill patients," Computer Methods and Programs in Biomedicine, vol. 102, pp. 192-205, 2011.

[9] L. Fisk, A. Le Compte, G. Shaw, S. Penning, T. Desaive, and J. Chase, "(2012) development and pilot trial results of stochastic targeted (star) glycemic control in a medical icu," Budapest, Hungary: 8th IFAC Symposium on Biological and Medical Systems (BMS12), 29-31 Aug 2012. Biological and Medical Systems, , vol. 8, no. 1, pp. 301-306, 2012.

[10] R. E. Shangraw and J. G. Hexem, "Glucose and potassium metabolic responses to insulin during liver transplantation." Liver Transpl Surg, vol. 2, no. 6, pp. 443-54, 1996. [Online]. Available: http://www.biomedsearch.com/nih/Glucose-potassium-metabolicresponses-to/9346691.html

[11] G. Perseghin, E. Regalia, A. Battezzati, S. Vergani, A. Pulvirenti, I. Terruzzi, D. Baratti, F. Bozzetti, V. Mazzaferro, and L. Luzi, "Regulation of glucose homeostasis in humans with denervated livers." J Clin Invest, vol. 100, no. 4, pp. 931-41, 1997.

[12] N. Cano, "Bench-to-bedside review: glucose production from the kidney." Crit Care, vol. 6, no. 4, pp. 317-21, 2002.

[13] N. Moller, R. A. Rizza, G. C. Ford, and K. S. Nair, "Assessment of postabsorptive renal glucose metabolism in humans with multiple glucose tracers." Diabetes, vol. 50, no. 4, pp. 747-51, 2001. [Online]. Available: http://www.biomedsearch.com/nih/Assessmentpostabsorptive-renal-glucose-metabolism/11289038.html

[14] A. Vella, A. S. Reed, N. Charkoudian, P. Shah, R. Basu, A. Basu, M. J. Joyner, and R. A. Rizza, "Glucose-induced suppression of endogenous glucose production: dynamic response to differing glucose profiles." Am J Physiol Endocrinol Metab, vol. 285, no. 1, pp. E25-30, 2003. [Online]. Available: http://www.biomedsearch.com/nih/Glucoseinduced-suppression-endogenous-glucose/12637258.html

[15] S. E. Joseph, N. Heaton, D. Potter, A. Pernet, M. A. Umpleby, and S. A. Amiel, "Renal glucose production compensates for the liver during the anhepatic phase of liver transplantation." Diabetes, vol. 49, no. 3, pp. 450-6, 2000. [Online]. Available: http://www.biomedsearch.com/nih/Renal-glucose-productioncompensates-liver/10868968.html 